\title{
EMG analysis of stereotyped voluntary movements in man
}

\author{
Mark Hallett
}

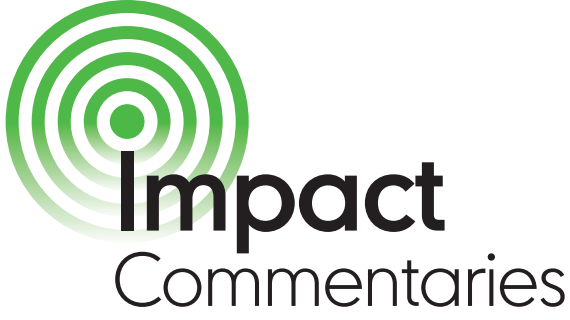

\begin{abstract}
Mark Hallett from NIH describes how understanding of motor control principles and opening a window on movement pathophysiology begins with a detailed analysis of the patterns of motor output
\end{abstract}

Movement is the principal output of the brain and the way that an organism interacts with the environment. One of the major goals of neuroscience is to understand how the brain makes movement; and one of the goals of neurology is to understand how the processes fall apart in different movement disorders. A good way to start the analysis of this set of problems is to analyse movement itself, from the bottom up. There are many degrees of freedom of the body and movements could be accomplished in many different ways. As central nervous systems have evolved they have certainly taken certain directions which simplify, and hopefully optimise, how movements are actually made. Measuring the EMG of muscles involved in the movement is a direct reflection of the motor commands. This paper looks at the EMG patterns in several types of normal voluntary movements and can be viewed as an introduction to analyses of how these patterns are normally made and can be used as a measure for characterising movement problems.

This paper was my first in the field of motor control. I was a membrane biophysicist and got interested in motor control by interacting with Edward Evarts, Ragnar Granit and Mahlon

Correspondence to Dr M Hallett, Human Motor Control Section, NINDS, NIH, 10 Center Drive MSC 1428, Bethesda, MD 20892-1428; hallettm@ninds.nih.gov
EMG ANALYSIS OF STEREOTYPED VOLUNTARY MOVEMENTS IN MAN ${ }^{1}$

Authors: Hallett M, Shahani BT, Young RR Year published: 1975

DeLong when I was a fellow at the National Institutes of Health (NIH). During my neurology residency that followed, neurology residents were encouraged to do research and Bhagwan Shahani convinced me to do this in the physiology laboratory that was supervised by himself and Robert Young. I wanted to follow-up a paper by Ronald Angel that we had read in a journal club at $\mathrm{NIH}^{2}$ and to use this information to start studying movement disorders.

In the work leading to this paper, I investigated normal slow and fast flexion movements at a single joint, the elbow. There had been some previous papers on the subject, beginning, of course, in the 'old' German literature, but the findings had not been consistent. Slow movements could just be continuous activity of the agonist muscle. The pattern of the fast, or ballistic, movement was stereotyped in the subjects and showed a triphasic pattern of sequential agonist, antagonist and agonist activity. These activities were in bursts and generally no more than $100 \mathrm{~ms}$ duration. When the antagonist muscle was active prior to a fast movement, it silenced with a pause before the agonist burst. There were also some experiments which added evidence to the idea that these patterns were centrally programmed, rather than resulting from spinal reflexes. One important bit of evidence was that all these patterns were present in a patient with a pan-sensory neuropathy.

I also began the work on movement disorders by doing similar studies in patients with cerebellar ataxia which led to a companion paper in JNNP that immediately followed the normal physiology study. ${ }^{3}$ This showed that the patterns were distorted in these patients. Prolonged EMG bursts appeared to underlie dysmetria and the failure of the antagonist silence prior to agonist activity was suggested to be a factor in dysdiadochokinesia. Analysis of other movement disorders followed over the next years. Another observation along these lines, also highly cited, was that bradykinesia in patients with Parkinson's disease is characterised by repetitive running of the triphasic pattern with low amplitude. ${ }^{4}$ This type of work, showing elemental movement patterns in disease, from my laboratory and others was largely completed by the late 90 's. ${ }^{5}$ These studies showed that slowness and incoordination from different pathologies might well look different. The collective work gives both a clinical neurophysiological tool for differential diagnosis and direction for further studies.

While these studies have clearly been valuable, they are indeed only the beginning of understanding the pathophysiology. We know what needs to be explained. More still needs to be learnt about how the CNS command is crafted to create these patterns and how it becomes distorted in disease. The way the motor cortex produces the basic triphasic pattern command is still not known. And, of course, there are also other elemental principles of motor control such as primitive movement modules, ${ }^{6}$ how to combine elemental movements into more complex movements, surround inhibition ${ }^{7}$ and motor learning.

First published in the Journal of Neurology, Neurosurgery and Psychiatry 1975;38:1154-62.

Competing interests None.

Provenance and peer review Commissioned; not externally peer reviewed.

Received 25 August 2011

Accepted 6 September 2011

J Neurol Neurosurg Psychiatry 2012;83:122-123. doi:10.1136/jnnp-2011-301283

\section{REFERENCES}

1. Hallett M, Shahani BT, Young RR. EMG analysis of stereotyped voluntary movements in man. J Neurol Neurosurg Psychiatry 1975;38:1154-62.

2. Angel RW, Garland H, Alston W. Interaction of spinal and supraspinal mechanisms during voluntary innervation of human muscle. Exp Neurol 1970;28:230-42. 
3. Hallett M, Shahani BT, Young RR. EMG analysis of patients with cerebellar deficits. J Neurol Neurosurg Psychiatry 1975;38:1163-9.

4. Hallett M, Khoshbin S. A physiological mechanism of bradykinesia. Brain 1980;103:301-14.
5. Berardelli A, Hallett M, Rothwell JC, et al. Review article. Single-joint rapid arm movements in normal subjects and in patients with motor disorders. Brain 1996;119:661-74.
6. Gentner R, Classen J. Modular organization of finge movements by the human central nervous system. Neuron 2006;52:731-42.

7. Hallett M. Neurophysiology of dystonia: the role of inhibition. Neurobiol Dis 2011:42:177-84.

\section{SAVE TIME AND KEEP INFORMED}

Joumal of

NEUROLOGY,

NEUROSURGERY

\& PSYCHIATRY

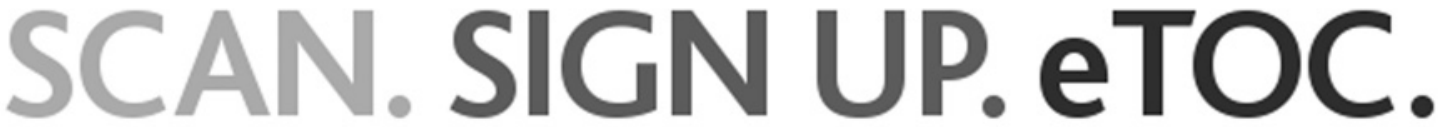

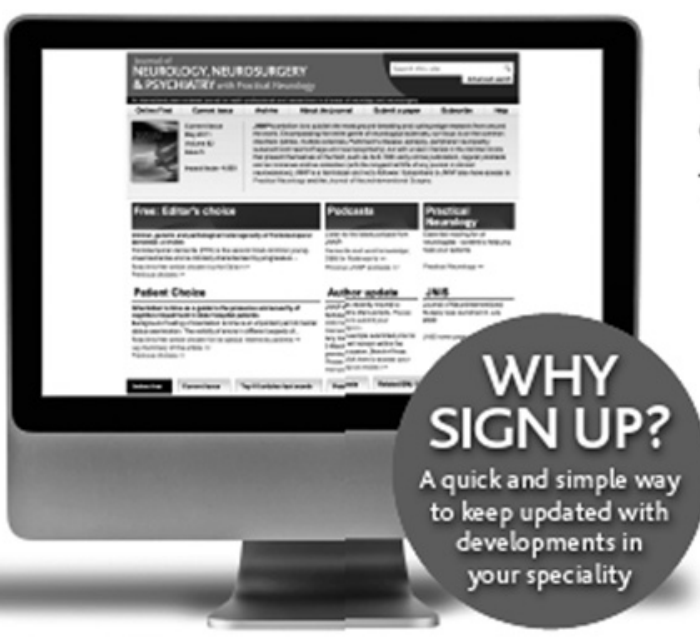

jnnp.bmj.com
Utilise our Quick Response code (QR) to sign up for our electronic table of contents (eTOC) alert.

To make this simple you can sign up now via your Smartphone.

\section{FOLLOWTHESE}

THREE EASY STEPS:

1. Downbad a free $Q R$ reader from your handset's app store

2. Hold your Smartphone over the QR code

3. You will then be forwarded to the eTOC sign up page

To find out more about $Q R$ codes visit

group.bmj.com/products/journals/qr-codes

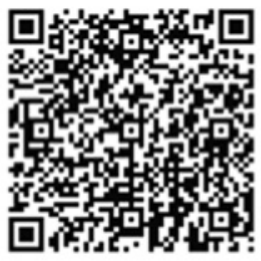

BMJIJournals 